\title{
SOCIO-ECONOMIC PROFILE AND MONTHLY INCOME OF FISHERMEN IN MARANG, TERENGGANU
}

\author{
MIZA NURSYAZWIN AND ALFIAN ZEIN* \\ School of Fisheries and Aquaculture Sciences, Universiti Malaysia Terengganu, 21030 Kuala Nerus, \\ Terengganu, Malaysia
}

Corresponding author: alfian.z@umt.edu.my

\begin{abstract}
This study was carried out in Marang, Terengganu. The objective of this study is to analyse the socio-economic profile of fishermen and their monthly income. The Slovin's formula was used to calculate the number of respondents in Marang and the data was collected through a survey involving 50 respondents consisting of Malay fishermen. The results of the study showed that the dominant types of fishing gear used were hooks and lines, gillnets and purse seines. The socio-economic profile showed that a majority of the fishermen (35\%) were aged between 40-49 years, $36 \%$ of the fishermen had between 10-19 years of experience, and 55\% of the fishermen had between 2-5 children. The average monthly income of the fishermen was MYR1853.49 for those using hooks and lines, MYR2105.09 for gillnets and MYR2595.39 for purse seines. It appears that the use of purse seines generated the highest income for the fishermen. Generally, the income was not fixed as it depended on the amount of catch for each fisherman's trip, which was also affected by the season.
\end{abstract}

Keywords: Socio-economic, fishermen, income, Marang, Terengganu

\section{Introduction}

According to Mazuki \& Man (2014), fishery sectors are built from two major parts, which are marine-fisheries and aquaculture, with marine-fisheries consisting of inshore fishing and deep-sea fishing. Artisanal fishermen usually work at the coastal water and they commonly use fishing vessels that are not technologically improved. In contrast to artisanal fishermen, commercial fishermen use bigger and technology-equipped vessels to operate at a further location out on the sea. These days, fishing vessels have undergone many evolutions that changed the way fishermen conduct their fishing operations. Fishing vessels with technology implementation have been proven to increase productivity and income, reduce

\section{Materials and Method \\ Location and Time}

This study was conducted in Marang, Terengganu. Marang District is located in the South China Sea Coast. The main economic unnecessary risks, improve communication quality and also save time (Mazuki \& Man, 2014). In this study, it was found that different fishing vessels were used by fishermen in Marang and each fishing vessel had different level of efficiency to catch fish based on the characteristics of the vessel. This characteristics affected the amount of catch, which then led to the different amount of income for each fisherman. Fish catch data is useful for formulation of policies to protect the resources and to manage people using them (Jacquet et al.,2010). This study is important as it shows a huge difference between the income of the fishermen, which was MYR1853.49, MYR2105.09 and MYR2595.39 for hooks and lines, gillnets and purse seines respectively, with the average national income per capita (MYR3282).

activity in Marang is fishery and there are nine main fish landing sites in Marang, including Kuala Marang, Pulau Terengganu, Kelulut, Rhu Muda, Kuala Merang, Rhusila and Cendering. 


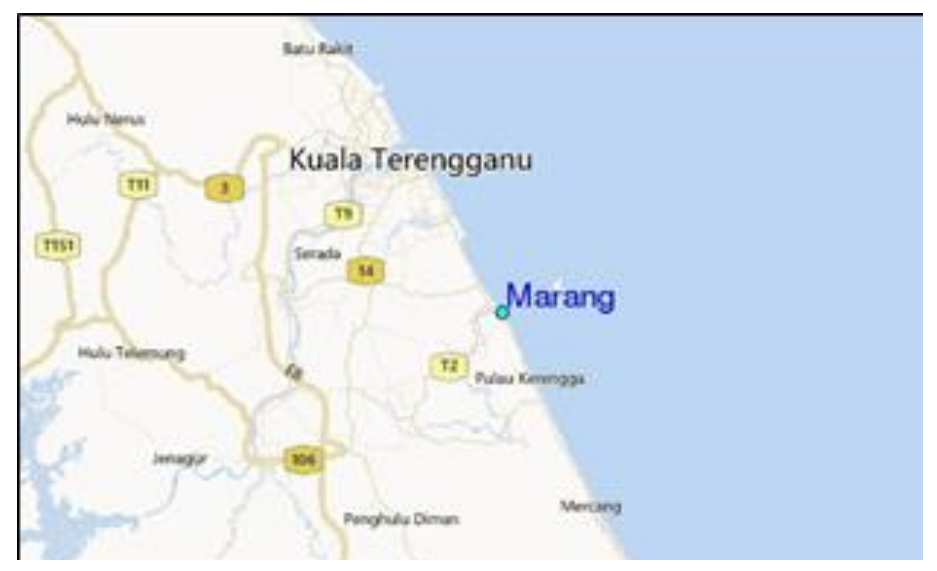

Figure 1 : Map of Marang, Terengganu, the study location.

\section{Data collection}

Data was collected through a survey of 50 of fishermen at Kuala Marang, Terengganu. The total number of sample were calculated using Slovin's formula.

$$
\begin{array}{|c|}
\hline \text { Slovin, } \mathrm{n}=\mathrm{N} /\left(1+\mathrm{Ne}^{2}\right) \\
\mathrm{n}=\text { No. of sample } \\
\mathrm{N}=\text { Total population } \\
\mathrm{e}=\text { Margin of error }
\end{array}
$$

The total population of fishermen at Kuala Marang is 827. This survey was conducted for 3 months, from January until March, 2018. Data was collected through interviews with the fishermen, and it included the socioeconomic status, fishing activities and their monthly general income.

\section{Data Analysis}

The data collected on socio-economic and demographic aspects was age, sex, family size, type of fishing vessel used, number of labour per vessel and range of income per month. This data was used to determine quantitatively the amount of income earned from fish catch and factors affecting fishermen's income (Adili \&
Antonia, 2017). To find out about the income-sharing system between owners and crew fishermen, descriptive analysis was used, and to analyse fishermen's income, income analysis was used, adhering to the formula below.

$$
\begin{array}{ll}
\text { I. } & \text { Total revenue }(\mathrm{TR})=\text { Price }(\mathrm{P}) \times \text { Quantity }(\mathrm{Q}) \\
\text { II. } & \text { Total cost }(\mathrm{TC})=\text { Variable cost }(\mathrm{VC})+\text { Fixed cost }(\mathrm{FC}) \\
\text { III. } & \text { Net profit }=\text { Total revenue }(\mathrm{TR})-\text { Total Cost }(\mathrm{TC})
\end{array}
$$

\section{Results and Discussion}

Fishermen in Marang, Terengganu

Generally, the number of fishermen at Kuala Marang was the highest compared to other districts in Marang such as Chendering, Rusila, Merchang, Jambu Bongkok, Pasir Putih and Gong Balai. Based on the data provided by Fisheries Development Authority of Malaysia (Lembaga Kemajuan Ikan Malaysia-LKIM) in Marang, the number of fishermen at Kuala Marang was 827, including local and foreign crews. All of the local crews were Malay Muslim males. 
A majority of the participants (35\%) were aged between $40-49$ years while a small number $(6 \%)$ were aged between 60-69 years. Generally, fishermen at active age are able to obtain high number of catch, and gain more income (Olaoye et al., 2012). However, the age of the participants varied in different study areas based on a few factors such as fertility, mortality and migration.

\section{$\square 20-29 \mathrm{y} / 0 \quad \square 30-39 \mathrm{y} / 0 \square 40-49 \mathrm{y} / 0 \quad-50-59 \mathrm{y} / 0 \quad \square 0-69 \mathrm{y} / 0$}

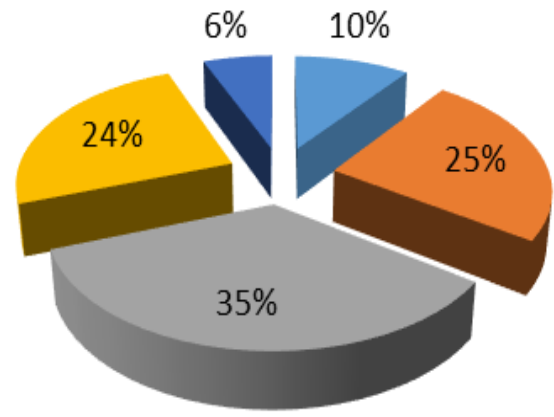

Figure 2: Age of fishermen in Marang

This survey showed that there was a high percentage of married fishermen, which was $90 \%$, while $10 \%$ of them were single. Being married affected the fishermen's daily expenditure as they have to be responsible for their household.

\section{- Single $\quad$ Married}

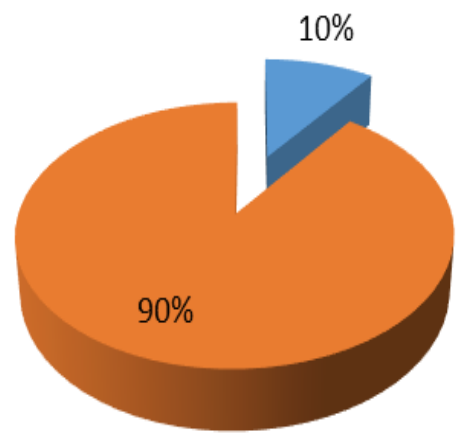

Figure 3: Marital status of fishermen in Marang

As shown in Figure 4, most of the respondents (36\%) had between 30 to 39 years of experience, $24 \%$ had between 20 to 29 years of experience, $20 \%$ had between 10 to 19 years of experience, $10 \%$ had between one to nine years of experience and $10 \%$ had between 40 to 49 years of experience. This data correlated with the age of the fishermen, suggesting that most of the fishermen in Marang have been involved in fisheries activities at a young age and this definitely increased their level of experience (Sharma et al., 2018). 


\section{" $1-9$ years $\square 10-19$ years $\square 20-29$ years $\square 30-39$ years $\square 40-49$ years}

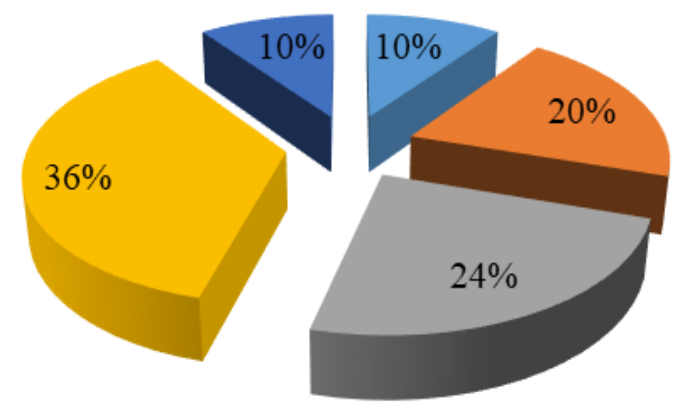

Figure 4: Fishing experience of fishermen in Marang

As shown in Figure 5, more than half of the respondents $(55 \%)$ had more than five children.
Meanwhile, $31 \%$ had less than five children and $14 \%$ had no children, as a few of them were still single.

\section{No child $\quad$ Below 5 Above 5}

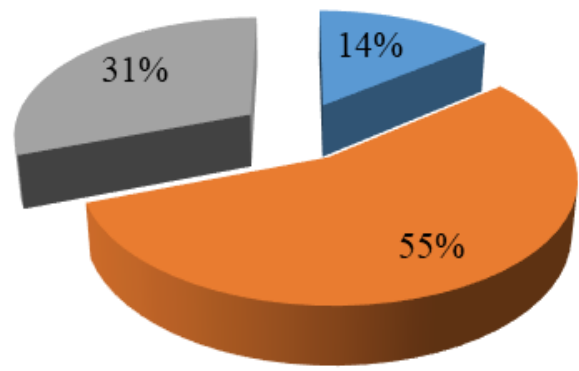

Figure 5: Number of children of fishermen in Marang

\section{Fishing Units}

At the time of the study, there were 3287 fishing vessels recorded in Terengganu, which represented $17 \%$ of total vessels in Peninsular Malaysia. As for Marang, information obtained stated that it was a large fishing zone with vessels situated there, while for Kuala Marang, there were 293 vessels recorded. From the number, 174 were for inshore, 91 worked at Zone A, 21 worked at Zone B, and 7 worked at Zone C. At A zone, the types of fishing gear were hooks and lines, gillnets, traps, lift nets, trawls and anchovies purse seines. Meanwhile, at B zone, the types of fishing gear were trawls, fish purse seines, and traps which were in fewer numbers compared to the
A zone. At $\mathrm{C}$ zone, only few numbers of fishing gear were used which included trawls, drag nets, fish purse seines, gillnets, hooks and lines and also traps.

\section{Types of Fishing Gear}

A total of 50 respondents were selected in this study as they had dominant types of fishing gear. The dominant types of fishing gear at Kuala Marang were purse seines, hooks and lines and gillnets. Basically, 25 of the total respondents $(50 \%)$ worked with hooks and lines at $\mathrm{A}$ zone, 16 of them (32\%) worked with gillnets at A zone, while 9 of them (18\%) worked with purse seines at B zone. 


\section{Purse seine $\quad$ Hook and line $\quad$ Gill net}

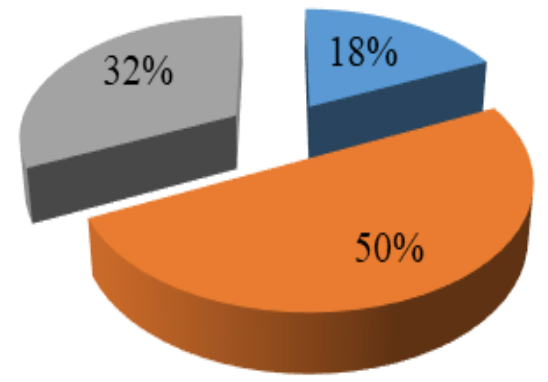

Figure 6 : Types of fishing gear used by fishermen in Marang.

\section{Number of Crew}

Most of the respondents who used purse seines (77.78\%) worked with 12 crew members and above, and $22.22 \%$ of them worked with 7 to $11 \mathrm{crew}$ members. As for hooks and lines, most of them (72\%) worked alone and $28 \%$ of them worked with 2 to 6 crew members. Meanwhile, for gillnets, all of them worked with 2 to 6 crew members in each fishing operation.

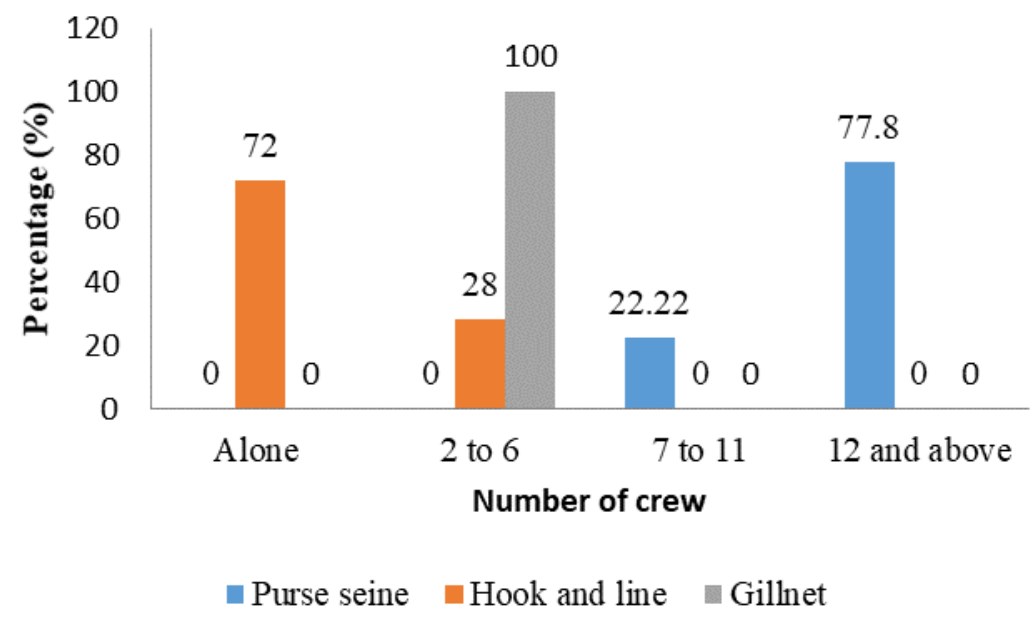

Figure 7: Number of crew on each fishing vessel

\section{Fishing Trips}

The number of trips per month varied among fishermen using purse seines, hooks and lines, and gillnets. All fishermen using purse seines went on a fishing trip 1 to 5 times per month, for the duration of 3 to 5 days per trip. Most fishermen using hooks and lines (14) went on a fishing trip 11 or more times in a month, for the duration of 5 to 6 days each trip. The other 10 respondents went on a fishing trip 6 to 10 times per month, and one of them went on a fishing trip 1 to 5 times each month. As for the fishermen using gillnets, 9 went 1 to 5 times per month, while 7 went 6 to 10 times per month. This showed that fishing duration for fishermen using hooks and lines was shorter compared to those of purse seines as they went on a fishing trip more frequently in a week. 


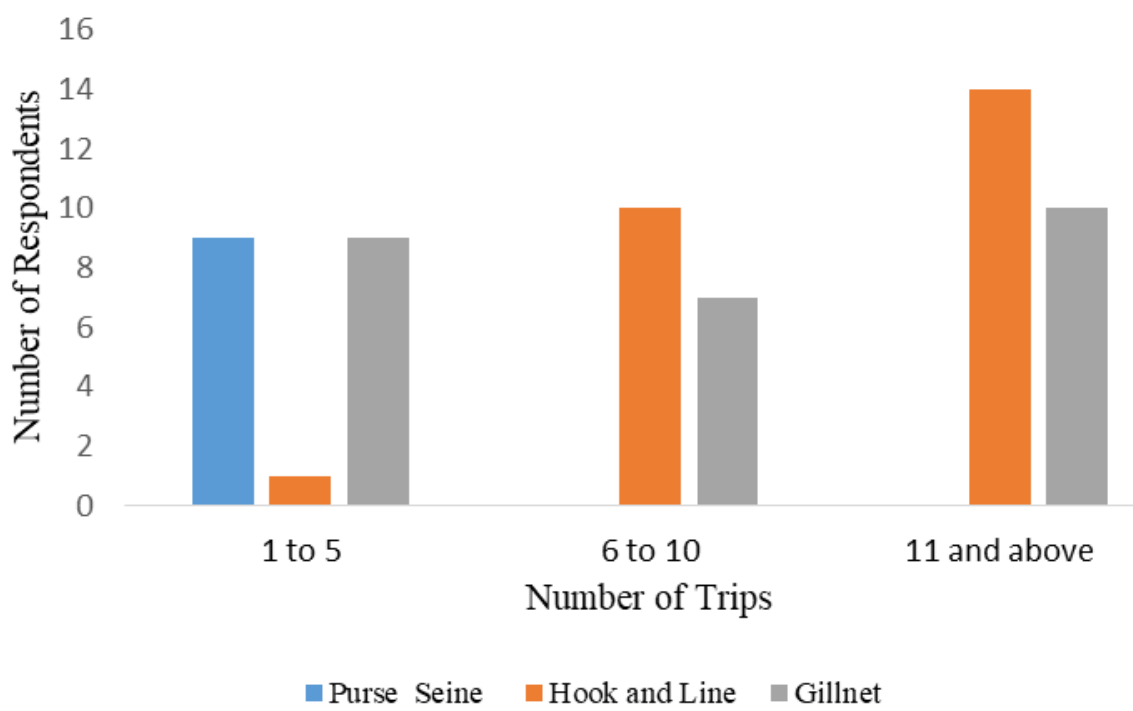

Figure 8: Number of fishing trips for each fisherman in Marang

\section{Investment}

The cost of investment for fishing gear was also different as each was using different technology and equipment. Purse seines incurred the highest investment of MYR186066.67. Gillnet investment was the second highest at MYR77287.5, while hooks and lines recorded the lowest average cost of investment, which was MYR73832.8.

\section{Revenue}

The total revenue was different among fishermen based on fishing gear used, whether purse seines, hooks and lines, and gillnets. The fishermen using purse seines recorded the highest revenue, as the number of catch was high for this fishing gear. Fishermen using gillnets recorded the second highest revenue, while fishermen using hooks and lines had the lowest revenue recorded. This revenue was also dependent on the price of the fish. Basically, using purse seines generated the highest number of fish caught, at an average of $6277.78 \mathrm{~kg}$ of fish per trip. Using gillnets generated the second highest average number of catch, which was $114.06 \mathrm{~kg}$, while using hooks and lines recorded an average of $35.2 \mathrm{~kg}$ of catch per trip. Figure 9 shows the average number of catch per trip for each type of fishing gear.

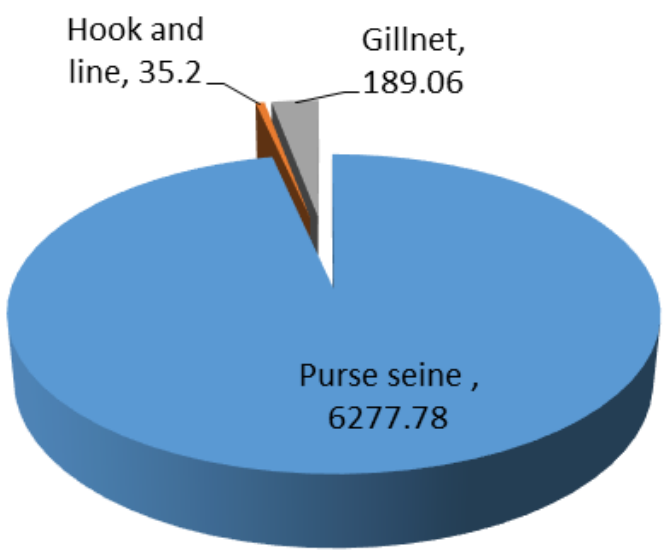

Figure 9: Number of catch/trip

The highest revenue was obtained when using purse seines, which was MYR 134955.56. As for using gillnets, MYR 11213.13 was generated each month, while when using hooks and lines, MYR 4056.92 was earned each month. 


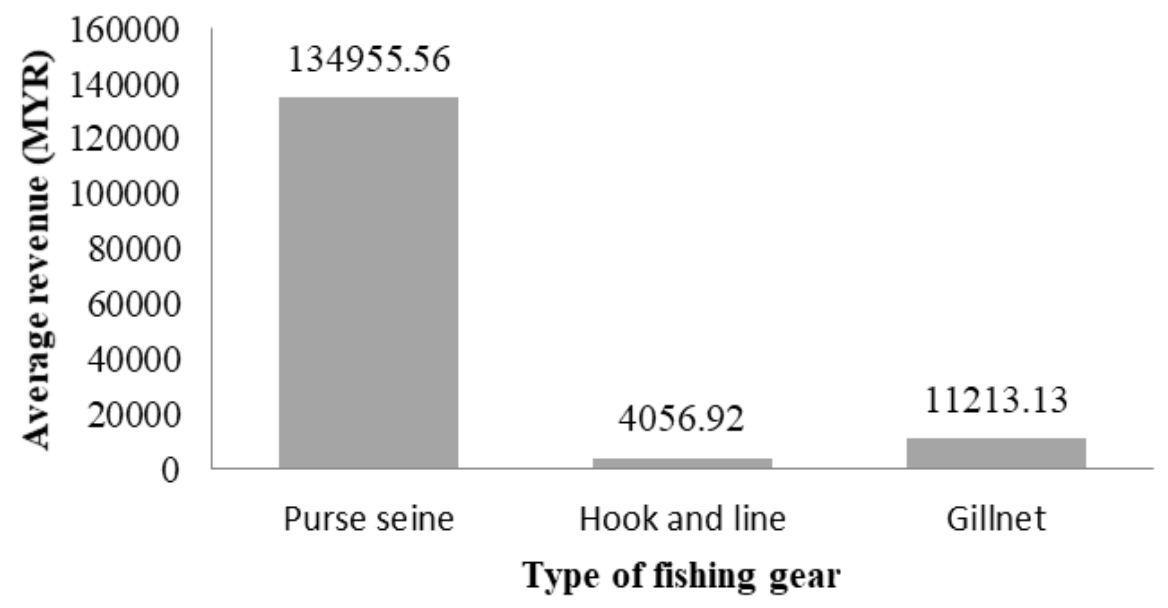

Figure 10: Average revenue per month

\section{Cost}

The cost involved in the fishing operation was variable cost and fixed cost. Fixed cost involved the cost of repairing vessels and license fees. Variable cost included the cost of ice and fuel used during the fishing operation, and also the cost of food consumed during the fishing activity. Based on the results, the average variable cost per trip for purse seining activity was MYR 6575.56, for hook and line MYR 236.92 and for gillnet MYR 247.38, which showed that purse seining activity incurred higher variable cost compared to those of hook and line fishing and gillnetting. The trend was the same for fixed cost incurred by each fishing gear.

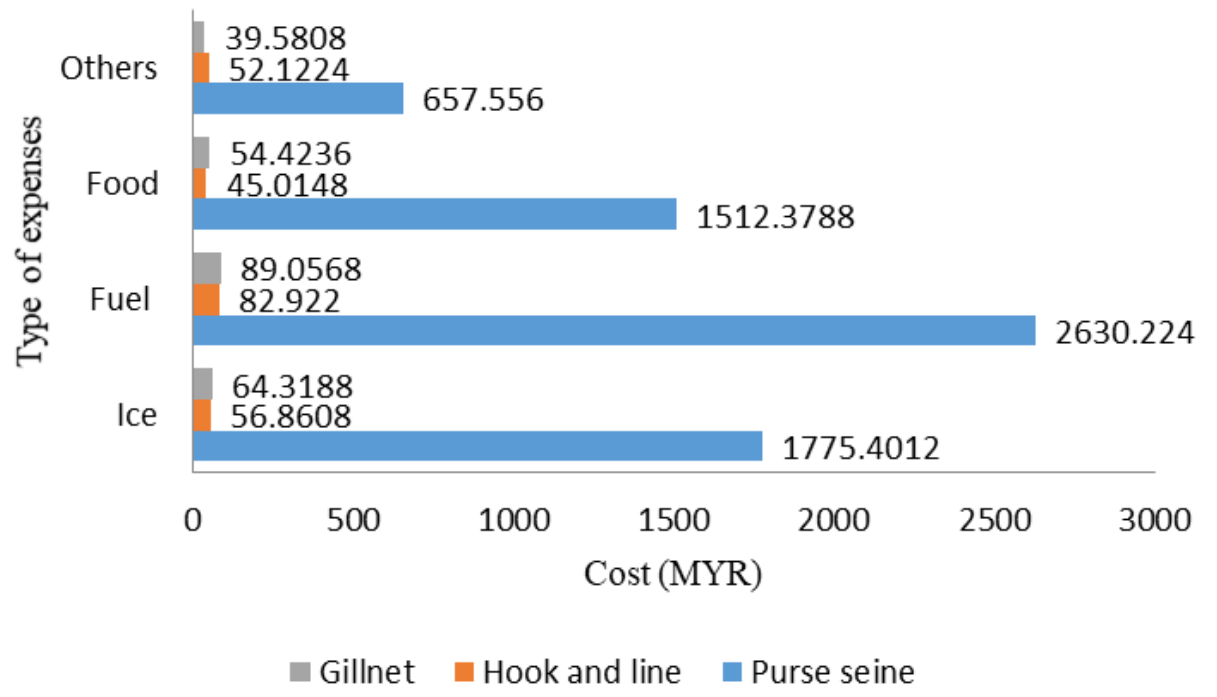

Figure 11: Variable cost per trip

\section{Income analysis}

The result of analysis showed that most of the fishermen in Marang practised income-sharing system, where gross income was divided into a few parts to be allocated to each of the crew on the boats. In order to calculate the income allocation between owners and the crew, the net income was calculated first by subtracting the total cost from the total revenue. Income-sharing system practised in Marang allocated $50 \%$ of net income to owners and $50 \%$ to the crew. 


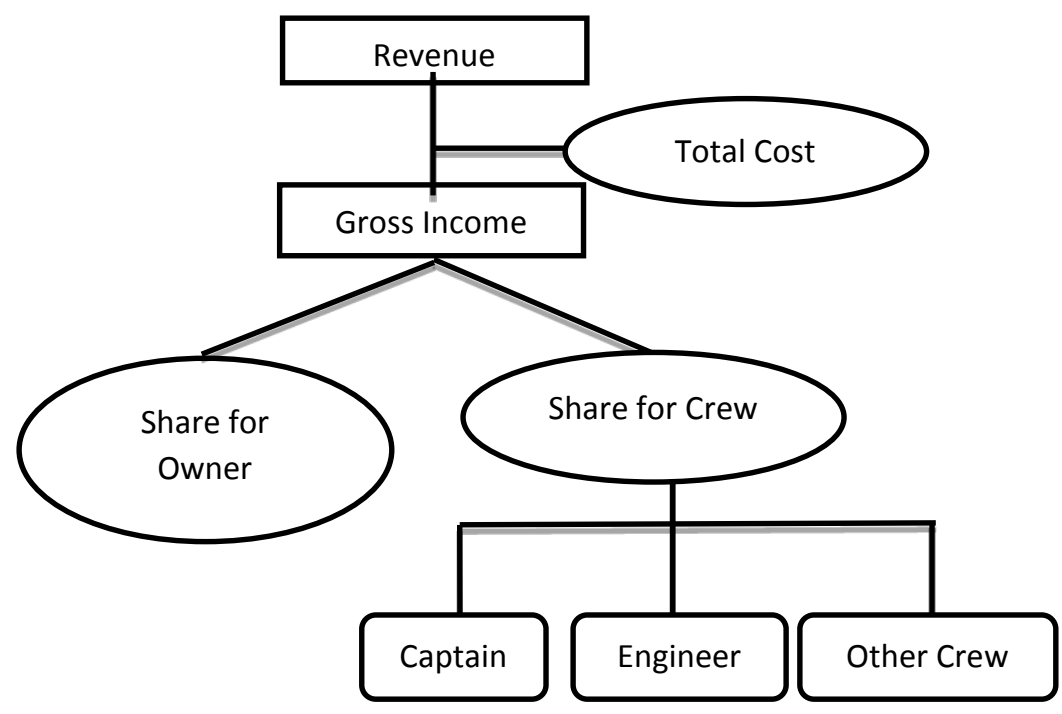

Figure 12: Income-sharing system between owner and crew members

Based on the system, the crew fishermen received smaller amount of income. In this study, all of respondents were the crew and therefore got the least amount of income.

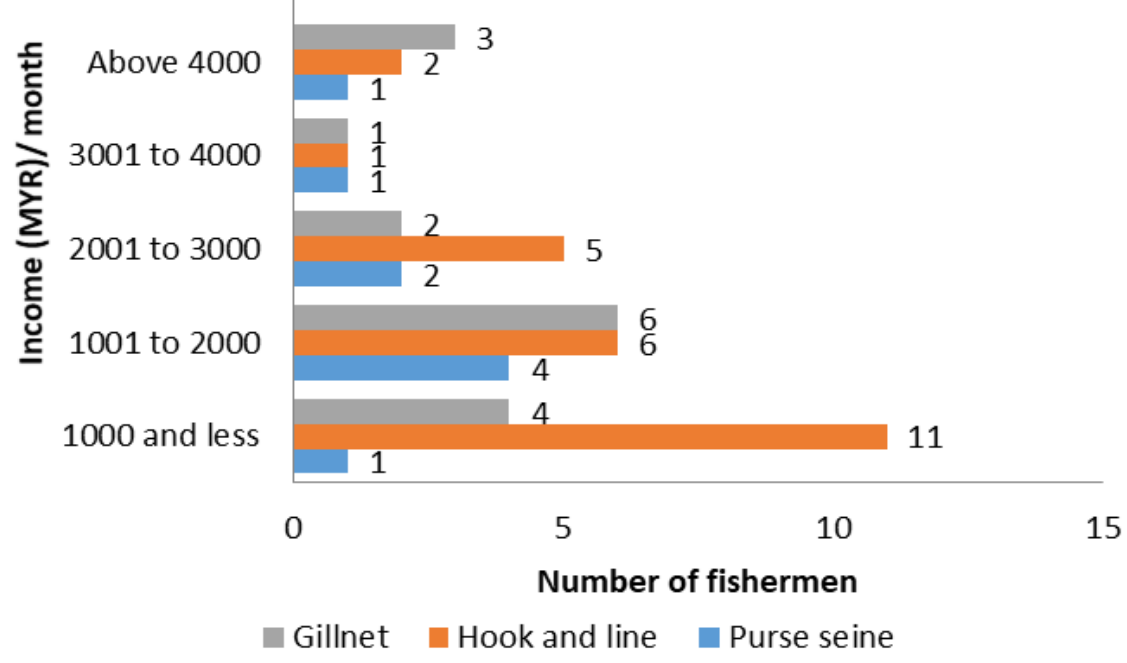

Figure 13: Monthly income of fishermen in Marang

Generally, the characteristics of fishing gear, namely size, gross tonnage (GRT), and type of engine (HP), and of the fishing ground, such as the number of fishing trip, fishing duration, zone of fish capture also affected the number of catch. The total cost which included fixed cost (licensed, repairing of vessels) and operating cost (ice, fuel, foods) for each fishing gear was also different. Purse seines incurred the highest cost that might be due to their characteristics compared to hooks and lines, and gillnets. As for the revenue, it was affected by the number of catch. Purse seines yielded the highest number of catch and more variety of types of fish as it operated at further fishing zone (zone C) compared to hooks and lines, and gillnets.

From the revenue and total cost, the income of fishermen was calculated. After income-sharing system was was used to divide gross income into individual income, it was found that fishermen using purse seines had the highest income (MYR2595.64) compared to hooks and lines (MYR1853.49) and gillnets (MYR2105.09).

\section{Conclusion}

The condition of socio-economic status of the fishermen family in Marang, Terengganu as reduced from the profile that included age, marital status, fishing experience and number of children were at low level. The three types of most dominant fishing gear in Marang, Terengganu, were purse seines, hooks and lines and gillnets. The highest income earned was from purse seining activity, followed by gillnetting and the last one being hook and lining, which was MYR 2,595.39, MYR 2,105.09 and MYR 1,853.47 per month respectively. This level of fishermen's income is still far from the average national income per capita (MYR3282). This indicates that there is still a gap between traditional fishermen and modern fishermen, and this gap needs to 
be closed by using appropriate measures, such as fisheries education and fishing ban (Bhendarkar et al., 2017). There were several factors that affected the fishermen's income including the number of catch and the effectiveness of fishing gear used. Increase in fishing production only contributes towards improving national income, instead of supporting fishermen's life (Mohsin et al., 2015). In this study, it was found that most of fishermen in Marang, Terengganu, practised incomesharing system in which net income was divided into few parts for owners and the crew. This study proposes that the use of illegal fishing gear should be prohibited and monitored properly.

\section{Acknowledgement}

The authors would like to thank the Fisheries Development Authority of Malaysia (LKIM), Marang, for the opportunity to collect primary and secondary data from LKIM Marang and the fishermen community in Marang. The author would also like to thank the School of Fisheries and Aquaculture Sciences, Universiti Malaysia Terengganu for granting permission for this study.

\section{References}

Adili, Z., \& Antonia, M. (2017). Determinants Influencing Fishing Income to The Coastal Households of Indian Ocean. Oceanography and Fisheries Open Access Journal, 4(3), 1-7.

Bhendakar, M. P., Sarang, N., Bhosale, M., Rathod, R. H., Laxmi \& Vardia, H. K. (2017). A Study on Profile of Socio-economic Condition of Fishermen in Selected Village in Kabirdham District, Chattisbarh State, India. International Journal of Educational Science and Research (IJESR), 7(6), 49-56.

Jacquet, J., Zeller, D \& Pauly, D. (2010). Counting Fish: A Typology for Fisheries Catch Data. Journal of Integrative Environmental Sciences, 7(2), 135-144.

Mazuki, R., \& Man, N. (2014). Acceptance of Technology among Malaysian Fishermen. Canadian Center of Science and Education, 10(16), $1-5$.

Mohsin, M., Yongtong, M., Hussain, K., Mahmood, A., Zhaoqun, S., Nazir, K \& Wei, W. (2015). Contribution of Fish Production and Trade to the Economy of Pakistan. International Journal of Marine Science, 5(18), 1-7.

Olaoye, O. J., Idowu, A. A., Omoyinmi, G. A. K., Akintayo, I. A., Odebiyi, O. C., \& Fasina, A. O. (2012). Socio-Economic Analysis of Artisanal Fisher Folks in Ogun Water-Side Local Government Areas of Ogun State, Nigeria. Global Journal of
Science Frontier Research Agriculture \& Biology, 12(4).

Sharma, S., Kumar, R., Kumar, M., Shubham, G., Maurya, P. K \& Singh, P. (2018). A Study on Socioeconomic Status of Fishermen of Amethi District, Uttar, Pradesh, India. International Journal of Fisheries and Aquatic Studies, 6(4), 49-54. 